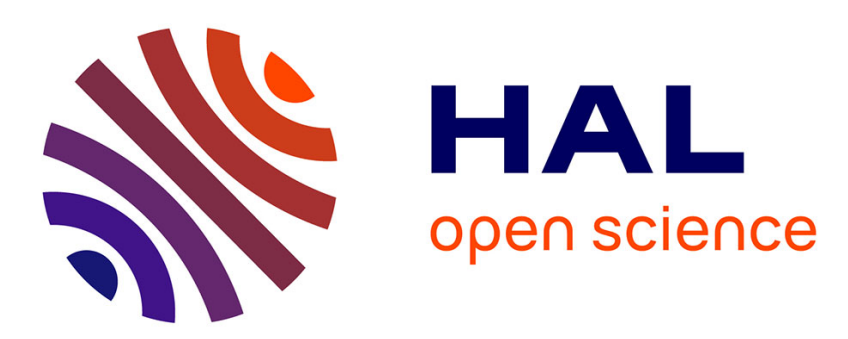

\title{
Boronic Acid-Functionalized Oxide-Free Silicon Surfaces for the Electrochemical Sensing of Dopamine
}

\author{
Bruno Fabre, Fanny Hauquier
}

\section{To cite this version:}

Bruno Fabre, Fanny Hauquier. Boronic Acid-Functionalized Oxide-Free Silicon Surfaces for the Electrochemical Sensing of Dopamine. Langmuir, 2017, 33 (35), pp.8693-8699. 10.1021/acs.langmuir.7b00699 . cea-01551024

\section{HAL Id: cea-01551024 \\ https://hal-cea.archives-ouvertes.fr/cea-01551024}

Submitted on 29 Jun 2017

HAL is a multi-disciplinary open access archive for the deposit and dissemination of scientific research documents, whether they are published or not. The documents may come from teaching and research institutions in France or abroad, or from public or private research centers.
L'archive ouverte pluridisciplinaire HAL, est destinée au dépôt et à la diffusion de documents scientifiques de niveau recherche, publiés ou non, émanant des établissements d'enseignement et de recherche français ou étrangers, des laboratoires publics ou privés.

\section{(c) (1) $\$$}

Distributed under a Creative Commons Attribution - NonCommerciall 4.0 International 


\title{
Boronic Acid-Functionalized Oxide-Free Silicon
}

\section{Surfaces for the Electrochemical Sensing of}

\section{Dopamine}

\author{
Bruno Fabre ${ }^{1, *}$ and Fanny Hauquier ${ }^{2}$ \\ ${ }^{1}$ Institut des Sciences Chimiques de Rennes, UMR 6226 CNRS, Matière Condensée et Systèmes \\ Electroactifs (MaCSE), Université de Rennes1, Campus de Beaulieu, 35042 Rennes Cedex, \\ France \\ ${ }^{2}$ Conservatoire National des Arts et Métiers, Analyse Chimique et Bioanalyse, EPN7, 292 Rue \\ Saint-Martin, 75003 Paris, France- NIMBE, CEA, CNRS, Université Paris-Saclay, CEA Saclay \\ 91191 Gif-sur-Yvette, France
}

KEYWORDS. Silicon, Boronic Acids, Dopamine, Monolayer, Electrochemical Sensing

ABSTRACT. Boronic acid monolayers covalently bound to hydrogen-terminated $\mathrm{Si}(111)$ surfaces have been prepared from the UV-directed hydrosilylation reaction of 4vinylbenzeneboronic acid. X-ray photoelectron spectroscopy (XPS) analysis of the modified surface revealed characteristics peaks from the attached organic molecule with the expected molecular composition and without oxidation of underlying silicon. From XPS data, the surface 
coverage was estimated to be ca. $0.34 \pm 0.04$ ethylbenzene boronic acid chain per surface silicon atom (i.e. $\left.(4.4 \pm 0.5) \times 10^{-10} \mathrm{~mol} \mathrm{\textrm {cm } ^ { - 2 }}\right)$ which is consistent with a densely packed monolayer. The electrochemical impedance spectroscopy measurements performed at $\mathrm{pH} 7.4$ in the presence of the $\mathrm{Fe}(\mathrm{CN}) 6^{3-} / \mathrm{Fe}(\mathrm{CN})_{6}{ }^{4-}$ reporter couple showed specific dopamine-induced changes, as a result of the binding of the guest molecule to the immobilized boronate species. The charge transfer resistance $\left(R_{\mathrm{ct}}\right)$ was found to decrease from $4.9 \mathrm{M} \Omega$ to $14 \mathrm{k} \Omega$ upon increasing the dopamine concentration in the range $10 \mu \mathrm{M}-1 \mathrm{mM}$. Furthermore, the presence of the interfering ascorbic acid until a concentration of $10 \mathrm{mM}$ did not change significantly the electrochemical response of the functionalized surface. Comparative electrochemical data obtained at the reference ethylbenzene monolayer provided clear evidence that the immobilized boronic acid units were responsible for the observed changes.

\section{Introduction}

Owing to the high affinity of boronic acids with some diols (e.g., sugars and catecholamines), their irreversible immobilization on electrode surfaces has appeared as a promising strategy toward the development of electrochemical (bio)sensing devices. ${ }^{1,2}$ Among the procedures used for attaching such functional units onto conducting surfaces, the incorporation in self-assembled monolayers ${ }^{3,4,5,6,7,8,9,10,11}$ and in polymer films ${ }^{12,13,14,15,16,17}$ has been the most explored and some of these boronic acid-modified electrodes have been successfully applied for the electrical detection of sugars ${ }^{1,4,12,13}$ and catecholamines. ${ }^{1,6,7,14,16,17}$ Compared with polymer films, the monolayer approach offers some advantages because it allows a molecular-level control of the functional layer structure (homogeneity, ordering and packing density) which makes, for example, more sensitive electrochemical detection. In that context, the functionalization of 
technologically important semiconducting surfaces, such as oxide-free, hydrogen-terminated silicon $(\mathrm{Si}-\mathrm{H})$ with molecular receptor-incorporating monolayers could constitute an attractive approach for designing novel interfaces for chemical/biological sensing. Indeed, Si-H has been demonstrated to be a particularly appealing substrate for electrochemical applications owing to the ease and reproducibility of its preparation, ${ }^{18,19}$ its well-defined structure, its very low density of electrically active surface defects, ${ }^{20}$ and its propensity to be chemically modified with organic monolayers linked through nonpolar and robust interfacial Si-C bonds. ${ }^{21,22,23,24,25,26,27}$ Moreover, unlike most of traditional electrodes (e.g. glassy carbon) used as working electrodes for the electrochemical sensing, silicon-based devices can be directly integrated within existing electronic circuitry ${ }^{28,29}$ and the numerous existing technological processes used for the microand nanopatterning of silicon are mature enough for producing highly miniaturized functional electronic components. For these reasons, such functional interfaces should show great promise for the monitoring of molecules of biological interest. Furthermore, it is noteworthy that the electrochemical detection of dopamine from a functionalized silicon surface is unprecedented.

Herein, we describe our results on the derivatization of $\mathrm{Si}(111)$-H surfaces with boronic acidterminated monolayers. These surfaces were produced by direct hydrosilylation of $\mathrm{Si}(111)-\mathrm{H}$ with vinylbenzeneboronic acid. They were thoroughly characterized by various experimental techniques including contact angle goniometry, X-ray photoelectron spectroscopy (XPS) and atomic force microscopy (AFM). The electrochemical response of the boronic acid-modified surfaces was then used as the signal transduction pathway of the binding event between the immobilized boronic acid moieties and dopamine. To highlight the role of boronic acid group in the dopamine detection, a reference ethylbenzene monolayer on silicon was also prepared and electrochemically studied in the presence of the target guest. 
It is worth emphasizing that the quantitative determination of dopamine in physiological fluids is of great interest in medicine. This molecule plays an important role in neurotransmission and other physiological processes. ${ }^{30}$ Low levels in dopamine have been correlated to some neurodegenerative diseases, such as Parkinson's disease, or to mental disorders, such as schizophrenia and anorexia, whereas high levels may be associated with other health problems like pheochromocytoma. ${ }^{31}$ Different analytical techniques have been used to detect dopamine in biological samples, such as high-performance liquid chromatography (HPLC), ${ }^{32}$ capillary electrophoresis, ${ }^{33}$ HPLC coupled mass spectroscopy,${ }^{34}$ electrochemistry, ${ }^{35,36}$ and field-effect transistors. ${ }^{37}$ The electrochemical approach is very attractive because it is an easily scalable, costeffective method and allows dopamine determination with fast response time. However, for modified electrode-based electrochemical detection, attention must be paid to both the morphology and the ordering of the sensitive molecular layer which may impact on the measurement reproducibility.

\section{Experimental Section}

2.1. Reagents. Acetone (MOS electronic grade, Erbatron from Carlo Erba), anhydrous ethanol (RSE electronic grade, Erbatron from Carlo Erba), toluene (HPLC grade, Fisher Chemical) and methylene chloride (RSE electronic grade, Carlo Erba) were used without further purification. The chemicals used for cleaning and etching of silicon wafer pieces $\left(30 \% \mathrm{H}_{2} \mathrm{O}_{2}, 96-97 \% \mathrm{H}_{2} \mathrm{SO}_{4}\right.$, and $40 \% \quad \mathrm{NH}_{4} \mathrm{~F}$ solutions) were of semiconductor grade (Riedel-de-Haën). 4vinylbenzeneboronic acid (98\%, Sigma-Aldrich), styrene (>99\%, stabilized with 4-tertbutylcatechol, Sigma-Aldrich) and dopamine hydrochloride (99\%, Alfa-Aesar) were used as received. 


\subsection{Covalent Attachment of the Ethylbenzene and Ethylbenzeneboronic Acid}

Monolayers on Silicon. A single side polished silicon(111) shard $\left(1.5 \times 1.5 \mathrm{~cm}^{2}, 1-5 \mathrm{ohm} \mathrm{cm}\right.$ resistivity, $p$-type, boron doped, thickness $=525 \pm 25 \mu \mathrm{m}$, Siltronix) was sonicated for $10 \mathrm{~min}$ successively in acetone, ethanol, and ultrapure $18.2 \mathrm{M} \Omega \mathrm{cm}$ water (Purelab Classic UV from Veolia Water-STI). It was then cleaned in $3: 1 \mathrm{v} / \mathrm{v}$ concentrated $\mathrm{H}_{2} \mathrm{SO}_{4} / 30 \% \mathrm{H}_{2} \mathrm{O}_{2}$ at $100{ }^{\circ} \mathrm{C}$ for $30 \mathrm{~min}$, followed by copious rinsing with ultrapure water.

Caution: The concentrated $\mathrm{H}_{2} \mathrm{SO}_{4}: \mathrm{H}_{2} \mathrm{O}_{2}$ (aq) piranha solution is very dangerous, particularly in contact with organic materials, and should be handled extremely carefully.

The surface was etched with ppb grade $40 \%$ aqueous argon-degassed $\mathrm{NH}_{4} \mathrm{~F}$ for 15 min to obtain atomically flat, oxide-free hydrogen-terminated $\operatorname{Si}(111)$ surface $(\mathrm{Si}-\mathrm{H}){ }^{38}$ It was then dipped in argon-degassed ultrapure water for several seconds, dried under an argon stream, and transferred immediately into a Pyrex Schlenk tube containing 4-vinylbenzeneboronic acid (or styrene) at $10 \mathrm{mM}$ in toluene, previously deoxygenated at $100{ }^{\circ} \mathrm{C}$ for $1 \mathrm{~h}$ at least and then allowed to cool down to ca. $30-40^{\circ} \mathrm{C}$ before introducing the $\mathrm{Si}-\mathrm{H}$ substrate. After Ar was bubbled through the solution for $30 \mathrm{~min}$, the $\mathrm{Si}-\mathrm{H}$ surface was irradiated in a Rayonet photochemical reactor $(300 \mathrm{~nm})$ for $3 \mathrm{~h}$. The ethylbenzeneboronic acid-modified silicon surface (Si-EBBA) [or ethylbenzene-modified silicon surface (Si-EB)] was rinsed copiously with toluene, ethanol and methylene chloride, then dried under an argon stream.

2.3. Surface Characterizations. XPS measurements were performed using a VSW HA100 system with $\operatorname{MgK} \alpha$ photons at $54^{\circ}$ incidence and a $45^{\circ}$ takeoff angle. This angle is used to increase surface sensitivity, especially to check for Si-O bonds appearance. Spectra were fitted with a convolution of Lorentzian and Gaussian profiles using standard procedures. Binding energies are referenced to the main $\mathrm{C} 1 \mathrm{~s}$ peak which is set at $285.0 \mathrm{eV}$. 
AFM images were recorded with a PicoSPM II microscope from Molecular Imaging using conventional gold coated-silicon nitride (contact mode) tips from Scientec.

Water contact angles were measured with a homemade goniometer under ambient conditions using a horizontal light beam to illuminate the liquid droplet. Uncertainty $\pm 2^{\circ}$.

2.4. Electrochemical Characterizations. The impedance spectroscopy measurements were performed with an Autolab electrochemical analyzer (PGSTAT 20 potentiostat/galvanostat from Eco Chemie B.V., equipped with the GPES/FRA software) in a self-designed three-electrode Teflon cell. The amplitude of the ac signal was $10 \mathrm{mV}$ and the frequency was varied from 100 $\mathrm{kHz}$ to $0.1 \mathrm{~Hz}$ with a logarithmic distribution (50 frequencies). The working electrode, modified Si(111), was pressed against an opening in the cell bottom using a Viton O-ring seal. An ohmic contact was made on the previously polished rear side of the sample by applying a drop of an InGa eutectic (Alfa-Aesar, 99.99\%). The electrochemically active area of the Si(111) surface (namely, $1.1 \mathrm{~cm}^{2}$ ) was estimated by measuring the charge under the voltammetric peak corresponding to the ferrocene oxidation on $\mathrm{Si}(111)-\mathrm{H}$ and comparing this value to that obtained with a $1 \mathrm{~cm}^{2}-\mathrm{Pt}$ electrode under the same conditions. The counter electrode was a platinum foil and a potassium chloride saturated calomel electrode (SCE) was used as the reference electrode. The applied potential during the impedance measurements was fixed at the open circuit potential of the electrochemical cell in contact with the redox couple $\mathrm{Fe}(\mathrm{CN})_{6}{ }^{3-} / \mathrm{Fe}(\mathrm{CN})_{6}{ }^{4-}$, namely $0.15 \mathrm{~V}$ vs SCE. Potassium ferrocyanide (99\%, Acros) and ferricyanide (99\%, Sigma-Aldrich) were used at a concentration of $2 \mathrm{mM}$ in buffered aqueous solution ( $0.1 \mathrm{M}$ phosphate buffer, $\mathrm{pH} 7.4$ or 0.1 $\mathrm{M}$ acetate buffer, $\mathrm{pH}$ 4).

All electrochemical measurements were carried out inside a homemade Faraday cage at room temperature $\left(20 \pm 2{ }^{\circ} \mathrm{C}\right)$ and under a constant flow of argon. 


\section{Results and Discussion}

The Si-EBBA surface was prepared from the photochemical reaction of 4vinylbenzeneboronic acid at $300 \mathrm{~nm}$ for $3 \mathrm{~h}$ in the presence of $\mathrm{Si}(111)-\mathrm{H}$ (Scheme 1). This direct hydrosilylation route yielded a boronic acid-terminated monolayer covalently bound to the silicon surface through strong Si-C bonds. ${ }^{39}$ For comparison, a Si(111) surface was similarly modified by an ethylbenzene monolayer from styrene (Si-EB).

Static contact angles measured with water reveal, as expected, the hydrophilic character of the Si-EBBA surface compared with Si-EB, $40 \pm 2^{\circ}$ vs $94 \pm 2^{\circ}$. These values are in close agreement with those reported for other boronic acid-terminated monolayers bound to gold $\left(\sim 32^{\circ}\right)^{9}$ and ethylbenzene-modified silicon $\left(90^{\circ}\right)^{40}$ surfaces. Such a result precludes thus the formation of a mixed monolayer with some alkene groups protruding to the surface resulting from the reaction of boronic acid groups with either $\mathrm{Si}-\mathrm{H}$ or some hydroxyl species present on the silicon surface. ${ }^{41}$

SCHEME 1. Preparation of the Boronic Acid- and Ethylbenzene-Modified Silicon(111) Surfaces

$\mathrm{SiO}_{2}$ Si(111)

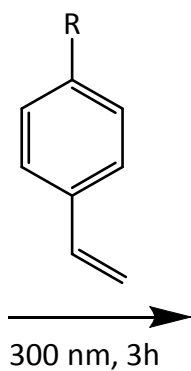

$$
\mathrm{R}=\mathrm{B}(\mathrm{OH})_{2} \text { Si-EBBA }
$$$$
=\mathrm{H} \quad \text { Si-EB }
$$

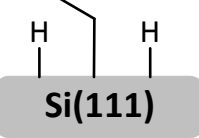

XPS. The X-ray photoemission spectroscopy (XPS) analysis of the silicon surface derivatized with the EBBA monolayer reveals characteristic peaks from the silicon substrate itself and from 
the $\mathrm{C} 1 \mathrm{~s}, \mathrm{O} 1 \mathrm{~s}$ and B 1s core levels of the attached organic molecule (Figure S1, Supporting Information). The experimental atomic ratios calculated from the peak areas of $\mathrm{O} 1 \mathrm{~s}, \mathrm{C} 1 \mathrm{~s}$ and $\mathrm{B}$ 1s were 2.7, 8.9 and 1.0, respectively (Table S1), which are in close agreement with the theoretical ratios calculated from the assumed structure of the boronic acid monolayer, namely 2 , 8 and 1 , respectively.

The high-resolution $\mathrm{C}$ 1s peak can be decomposed into two components at 285.0 and $286.7 \mathrm{eV}$ (Figure 1). The first one corresponds to unresolved contributions from both aromatic and alkyl carbon atoms, whereas the weaker peak at $286.7 \mathrm{eV}$ is reasonably attributed to heteroelementbound carbon $(\mathrm{C}-\mathrm{B})$. The $\mathrm{C}-\mathrm{C}+\mathrm{C}=\mathrm{C} / \mathrm{C}-\mathrm{B}$ atomic ratio (determined from the areas under the $\mathrm{C}$ $\mathrm{C}, \mathrm{C}=\mathrm{C}$ and $\mathrm{C}-\mathrm{B}$ peaks) was estimated at 8.0 , which is close to the theoretical ratio of 7 . The high-resolution B $1 \mathrm{~s}$ spectrum shows the presence of a peak located at $191.9 \mathrm{eV}$ attributable to boronic acid moieties overimposed with the broad Si satellite peak at $186.2 \mathrm{eV}$. These values are in good agreement with published values for boronic acid monolayers on $\operatorname{gold}^{3}$ and chlorobenzeneboronic acid. ${ }^{42}$

Moreover, the $\mathrm{Si} 2 \mathrm{p}$ signal shows as expected the presence of a principal component at $99.7 \mathrm{eV}$ attributed to $\mathrm{Si}-\mathrm{Si}$ bonds (Fig. 1c). Careful examination of the high binding energy side of Si 2p (near $104 \mathrm{eV}$ binding energy) does not show the presence of $\mathrm{Si}-\mathrm{O}$ bonds demonstrating no oxidation (or at a very low extent) of the underlying silicon surface and the formation of a boronic acid-terminated Si-C-linked monolayer.

The thickness of the organic monolayer $(d)$ has been estimated from the attenuation of the angular averaged silicon signal according to

$$
d=-\lambda_{\mathrm{Si}}^{\mathrm{mono}} \ln \left(\frac{I_{\mathrm{Si}, \text { mono }}}{I_{\mathrm{Si}, \text { clean }}}\right)
$$


where $\lambda \mathrm{si}^{\text {mono }}$ is the mean free path of the $\mathrm{Si} 2 \mathrm{p}$ electrons travelling through the organic layer $\left(\lambda_{\mathrm{si}}{ }^{\text {mono }}=3.6 \mathrm{~nm}\right)^{43}, I_{\mathrm{Si} \text {,mono }}$ and $I_{\mathrm{Si} \text {,clean }}$ are the $\mathrm{Si} 2 \mathrm{p}$ signals collected on grafted silicon and clean, uncovered $\mathrm{Si}(111)-\mathrm{H}$ surface, respectively.

The value of $1.4 \mathrm{~nm}$ found by this method is in close agreement with that deduced from calculations of energy minimization using the semiempirical PM3 method, considering the boronic acid units lifted up $(1.0 \mathrm{~nm})$. From XPS data and using the treatment reported by Cicero et al., ${ }^{44}$ the surface coverage can be estimated at $0.34 \pm 0.04$ ethylbenzene boronic acid chain per surface silicon atom, which is in perfect line with coverages determined for other UV-prepared monolayers derived from phenylacetylene. ${ }^{44} \mathrm{~A}$ specific area of about $35 \AA^{2}$ per bound ethylbenzeneboronic acid can thus be deduced, which is slightly greater than the maximum packing density of $25 \AA^{2}$ per molecule calculated by considering a $(2 \times 1)$ arrangement of aryl units on $\mathrm{Si}(111) .{ }^{45}$ This indicates a reasonably dense packing of the boronic acid-terminated chains. Our coverage value is however smaller than those estimated for other monoaromatic monolayers prepared under different conditions $(\sim 0.50)$, i.e. electrochemically ${ }^{45}$ or thermally. ${ }^{46}$ 

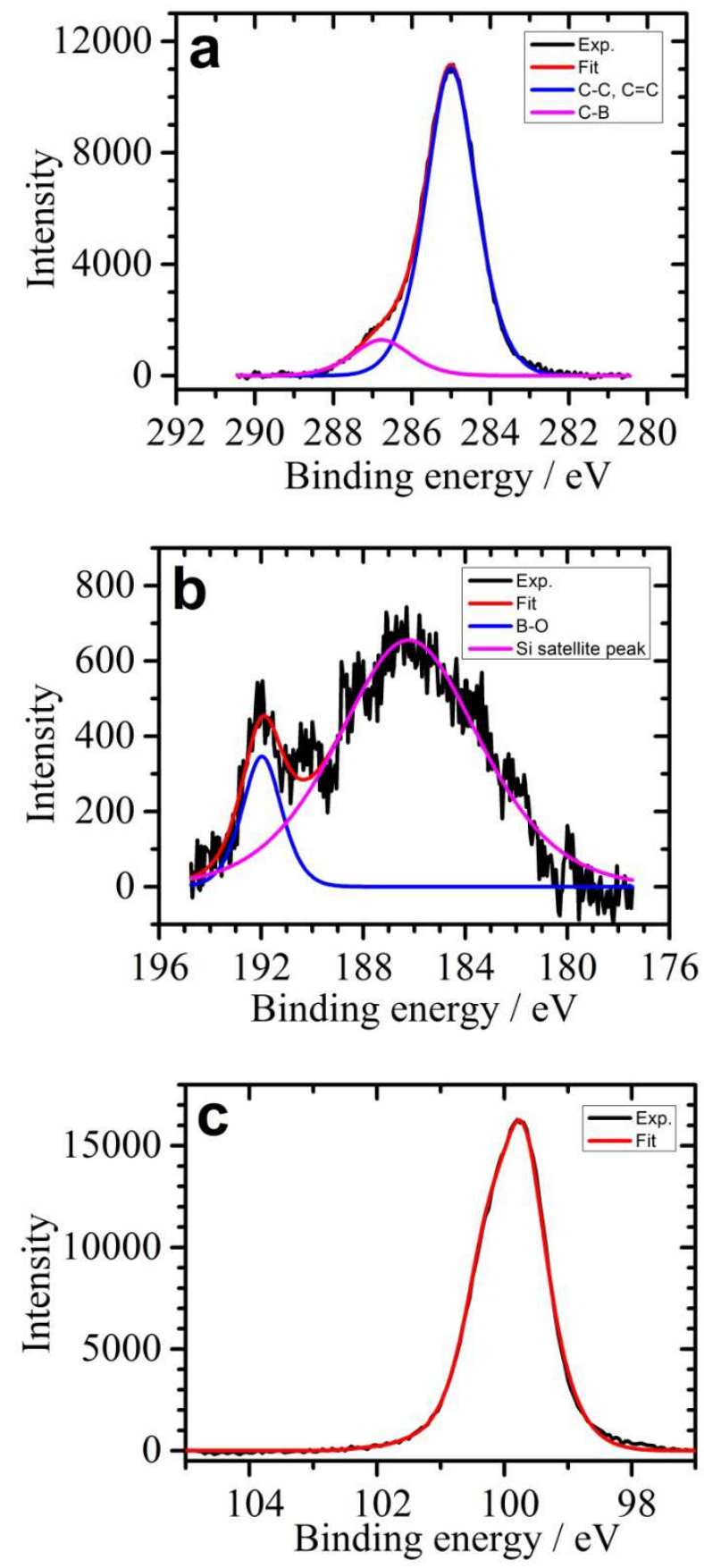

Figure 1. High-resolution XP C 1s (a), B 1s (b) and Si 2p (c) spectra of Si-EBBA. Black lines are experimental data and red lines are the fitted curves that were generated using combinations of Gaussian-Lorentzian functions, each corresponding to a different contribution. Spectra have been recorded at $45^{\circ}$ takeoff angle. 
AFM. Atomic force microscopy (AFM) analysis of the Si-EBBA surface shows a similar structure to that of $\mathrm{Si}(111)-\mathrm{H}$, with atomically flat, almost defect-free terraces consisting of about 3- $\AA$-high steps (Figure 2). This result indicates that the covalent attachment of the boronic acidterminated monolayer did not alter the underlying surface morphology. Moreover, any contrast in friction images is not observed and any adventitious material is not removed upon a prolonged AFM tip scanning on the same place. Therefore, it can be concluded that the molecular monolayer continuously covers the substrate without forming isolated patches and islands.
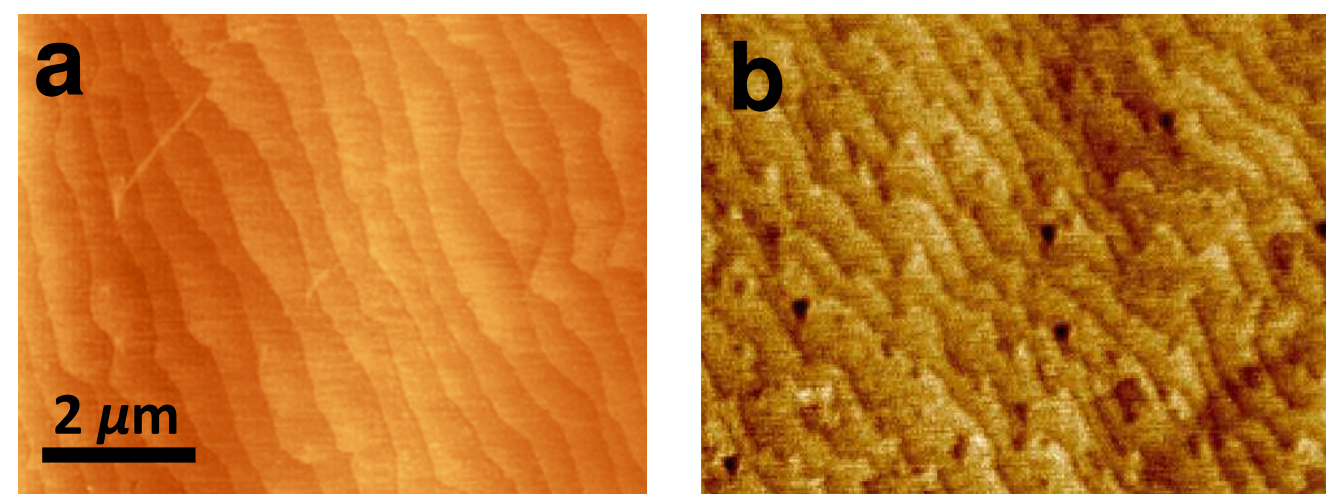

Figure 2. Contact-mode AFM images of $\mathrm{Si}(111)-\mathrm{H}$ (a) and Si-EBBA (b) surfaces.

\section{Electrochemical Sensing of Dopamine (DA) Using Impedance Spectroscopy.}

Electrochemical impedance spectroscopy (EIS) was used to quantitatively monitor the reaction of DA with the immobilized boronic acid moieties of the monolayer using the negatively charged $\mathrm{Fe}(\mathrm{CN})_{6}^{3-} / \mathrm{Fe}(\mathrm{CN})_{6}^{4-}$ as the reporter couple. Since the interaction of phenylboronic acid with DA is expected to be $\mathrm{pH}$ dependent, two different $\mathrm{pH}$ values were selected for sensing experiments, namely $\mathrm{pH} 4.0$ and 7.4. The $\mathrm{pH}$ value of 7.4 has been preferentially chosen to detect the binding of DA to the functionalized surface but also to prevent the polymerization of DA occurring 
usually at $\mathrm{pH}>8-8.5 .^{47}$ Moreover, since the two protonation sites of dopamine have $\mathrm{p} K_{\mathrm{a}}$ values of about 8.7 and 10.0 for the catechol and amine moieties, respectively, ${ }^{48}$ dopamine is predominantly in the form of a catechol molecule substituted by an ethylammonium chain at the two selected $\mathrm{pH}$ values.

The hydroxylation of phenylboronic acid occurs at weakly basic $\mathrm{pH}$, and under these conditions the resulting tetrahedral benzeneboronate ion can undergo covalent interactions with diols compounds (Scheme 2). ${ }^{1,49,50}$ This can be demonstrated by ${ }^{11} \mathrm{~B}$ NMR measurements in solution. The formation of the boronate form upon the dopamine binding at $\mathrm{pH} 7.4$ was supported by the presence of a signal at ca. $10 \mathrm{ppm}$ (Fig. S2), which was characteristic of the tetrahedral $\mathrm{sp}^{3}$ boron. ${ }^{51}$ In contrast, the ${ }^{11} \mathrm{~B}$ NMR spectrum of a vinylbenzeneboronic acid solution at $\mathrm{pH} 4$ showed the presence of one peak at ca. $29 \mathrm{ppm}$ which was assigned to a trigonal $\mathrm{sp}^{2}$ boron (Fig. S2). This signal was not significantly shifted after the addition of dopamine which indicates the absence of complexation at this $\mathrm{pH}$ value.

SCHEME 2. pH-Dependent Boronic Acid-Modified Silicon(111) Surface and Formation of the Boronate Ester Complex upon the Binding of Dopamine

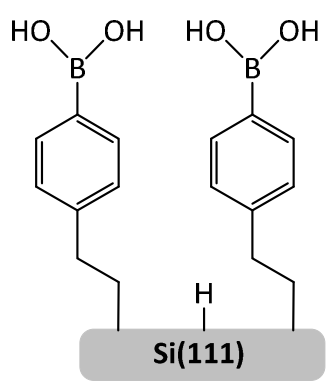

pH 4

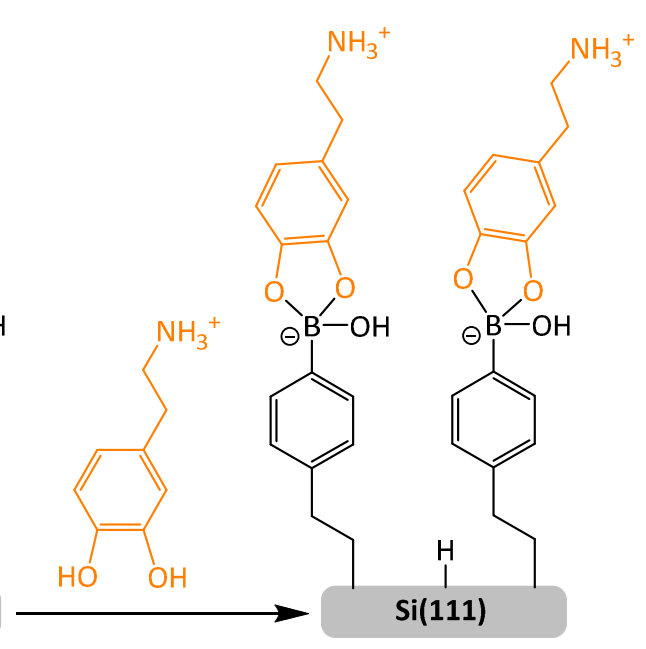

$\mathrm{pH} 7.4$ 
Furthermore, it is worth mentioning that the EIS measurements were performed after stabilization of the modified silicon surface (Si-EBBA or Si-EB) in the tested electrolytic buffer for at least $2 \mathrm{~h}$. This enabled to ensure a good reproducibility. Using such conditions, the relative uncertainty on the impedance values measured for equilibrated Si-EBBA or Si-EB in the absence or presence of dopamine was estimated at $10 \%$.

Figure 3 shows the EIS spectra in the frequency range $10^{5}-10^{-1} \mathrm{~Hz}$ of the Si-EBBA surface at two $\mathrm{pH}$ values in the absence and in the presence of $\mathrm{DA}$ and using the $\mathrm{Fe}(\mathrm{CN})_{6}{ }^{3-} / \mathrm{Fe}(\mathrm{CN})_{6}{ }^{4-}$ redox couple at the same concentration. The data are presented as plots of the imaginary part $\left(Z^{\prime \prime}\right)$ vs the real part $\left(Z^{\prime}\right)$ of the complex impedance $\left(Z=Z^{\prime}+\mathrm{i} Z^{\prime \prime}\right)$ as a function of frequency $f$ (Nyquist diagram). All Nyquist plots are characterized by a semicircle, the diameter of which is dependent on both the $\mathrm{pH}$ value and the presence or not of DA. The experimental data can be reasonably fitted assuming a Randles equivalent electrical circuit (Scheme 3). For this circuit model, the diameter of the semicircle on the $Z$ axis corresponds to the resistance of charge transfer $R_{\mathrm{ct}}$. In the absence of DA, the $R_{\mathrm{ct}}$ value determined at $\mathrm{pH} 7.4$ is almost two orders of magnitude higher than that estimated at $\mathrm{pH} 4$, namely $4.9 \mathrm{M} \Omega$ against $60 \mathrm{k} \Omega$ (Fig. 3a). This demonstrates that charge transfer kinetics of the $\mathrm{Fe}(\mathrm{CN})_{6}^{3-/ 4-}$ couple at the modified electrode is much slower at $\mathrm{pH}$ 7.4 than at $\mathrm{pH}$ 4. Such results are not surprising and can be easily explained by electrostatic effects. At $\mathrm{pH} 4$, the boronic acid units are globally neutral while at $\mathrm{pH} 7.4$, the diffusion of the redox probe across the monolayer is totally impeded due to strong electrostatic repulsions between the formed boronate anion $\mathrm{B}(\mathrm{OH})_{3}{ }^{-}$and $\mathrm{Fe}(\mathrm{CN})_{6}^{3-/ 4-}$.

Now, in the presence of DA, Nyquist plots at $\mathrm{pH} 4$ are not significantly modified because the guest is not able to bind to the immobilized boronic acid units (Fig. 3b). In contrast, a drastic decrease of $R_{\mathrm{ct}}$ upon increasing concentrations of DA is observed at pH 7.4 (Fig. 3c). The $R_{\mathrm{ct}}-$ 
(DA concentration) calibration curve displayed in Fig. 3d is characterized by an initial linear plot at low DA concentrations $(<0.2 \mathrm{mM}$ ) followed by a plateau for larger concentrations indicating that all the accessible binding sites in the monolayer are occupied. The detection limit is found to be below $10 \mu \mathrm{M}$. We have also checked that the addition of ascorbic acid, which is the principal interfering species in the dopamine detection, into a DA solution (at $1 \mathrm{mM}$ ) did not affect significantly the EIS response of the Si-EBBA surface until a tested concentration of $10 \mathrm{mM}$.

Also interestingly, the original state of this electrochemical sensor can be recovered after immersion of Si-EBBA in an acid medium $(\mathrm{pH} \sim 1-2)$ for few min. After this relatively simple chemical treatment, the EIS response is found to be similar to that before addition of dopamine, indicating that the free form of the immobilized boronic acid moieties has been regenerated.
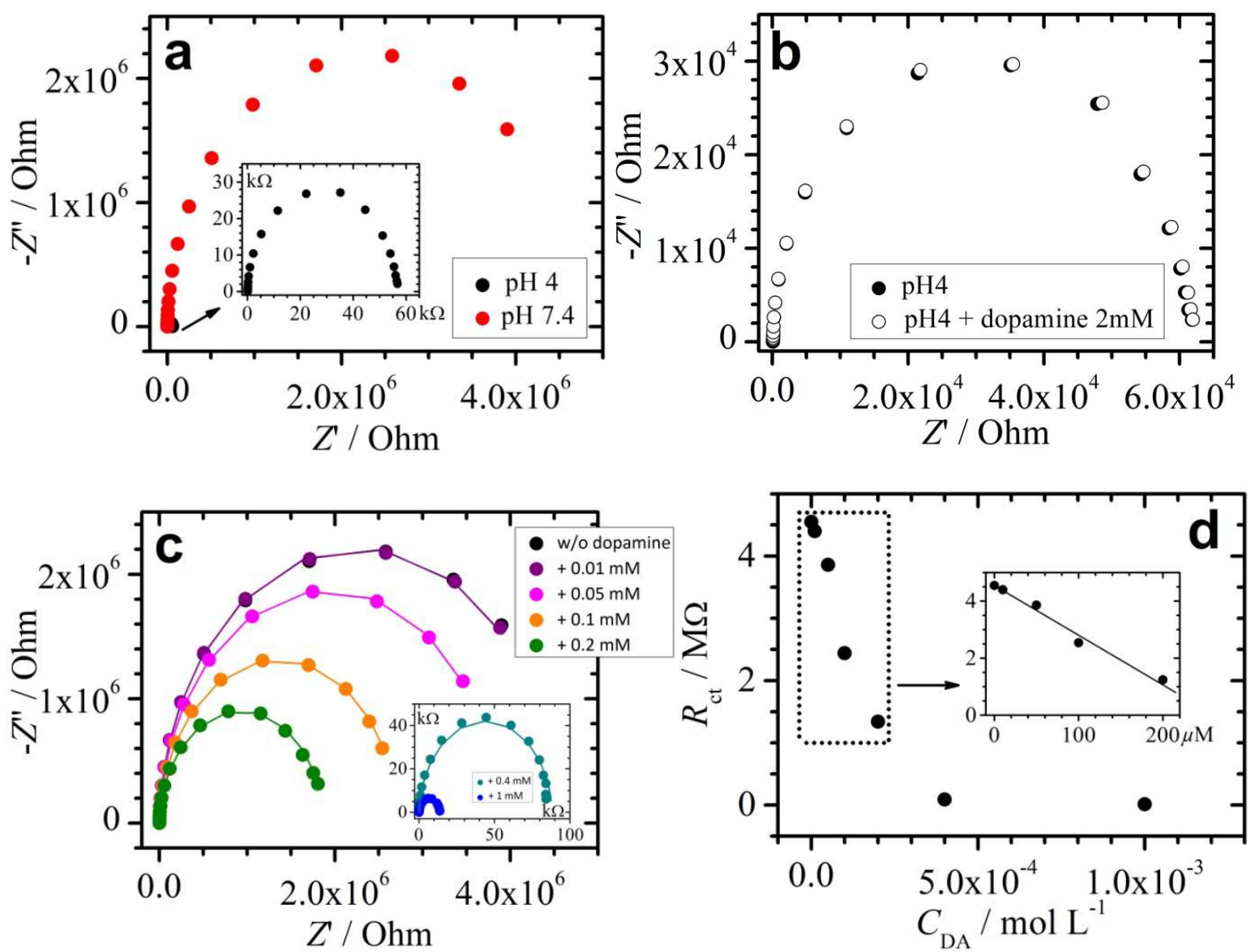
Figure 3. Nyquist (-Z" vs. $Z$ ) plots for the Si-EBBA surface at $\mathrm{pH} 4$ and 7.4 in the absence of dopamine (a), at $\mathrm{pH} 4$ in the presence of dopamine at $2 \mathrm{mM}(\mathrm{b})$, and at $\mathrm{pH} 7.4$ with increasing concentrations of dopamine (c). For (a-c), the applied potential was $0.15 \mathrm{~V}$ vs SCE and $\mathrm{Fe}(\mathrm{CN}) 6^{3-}$ $/ \mathrm{Fe}(\mathrm{CN})_{6}{ }^{4-}$ were present at $2 \mathrm{mM}$. The filled dots in (c) are the experimental data and the solid lines correspond to the fitted curves assuming a Randles equivalent electrical circuit. (d) Corresponding $R_{\mathrm{ct}}-$ (DA concentration) plot.

SCHEME 3. Proposed equivalent electrical circuit for electron transfer of $\mathrm{Fe}(\mathrm{CN}) 6^{3-} / \mathrm{Fe}(\mathrm{CN}) 6^{4-}$ reporter couple upon the binding of dopamine to the Si-EBBA surface. ${ }^{a}$

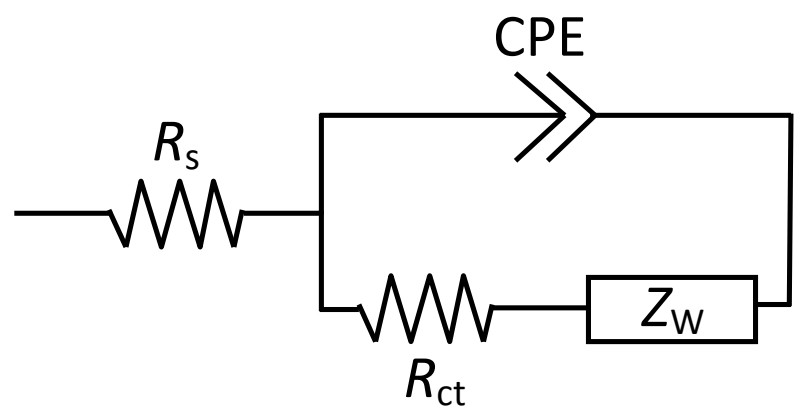

${ }^{a} R_{\mathrm{s}}$ is the solution resistance, $\mathrm{CPE}$ is a constant phase element, its impedance can be described as $Z_{\mathrm{CPE}}=\frac{1}{(i \omega)^{\alpha} C}$ where $C$ is the experimentally observed capacitance, $\omega$ is the angular frequency and $\alpha$ is generally a value between 0.9 and 1 ( $\alpha=1$ for an ideal capacitor). $Z_{\mathrm{w}}$ is the impedance due to mass transfer of the redox species to the electrode described by Warburg, $R_{\mathrm{ct}}$ is the chargetransfer resistance.

We have checked that the observed $R_{\text {ct }}$ changes were ascribed to the electrochemical activity of the redox probe alone. In the absence of the redox probe, the voltammetric oxidation of dopamine in solution to $o$-dopaminoquinone gives a quasi-reversible redox process at a formal potential $E^{\circ \prime}=0.35 \mathrm{~V}$ and $0.26 \mathrm{~V}$ (average of the anodic and cathodic peak potentials) at $\mathrm{pH} 4$ and 7.4, respectively (Fig. S3). Since the EIS measurements have been performed at $0.15 \mathrm{~V}$ vs 
SCE, it can be considered that dopamine was not electrochemically oxidized under such conditions at both considered $\mathrm{pH}$ values.

Moreover, comparison with EIS data obtained with the Si-EB surface provides clear evidence that DA-induced changes are ascribed to the immobilized boronic acid units. Indeed, as shown in Figure 4, the addition of DA to the ethylbenzene monolayer does not lead to significant changes in the $R_{\mathrm{ct}}$ values.
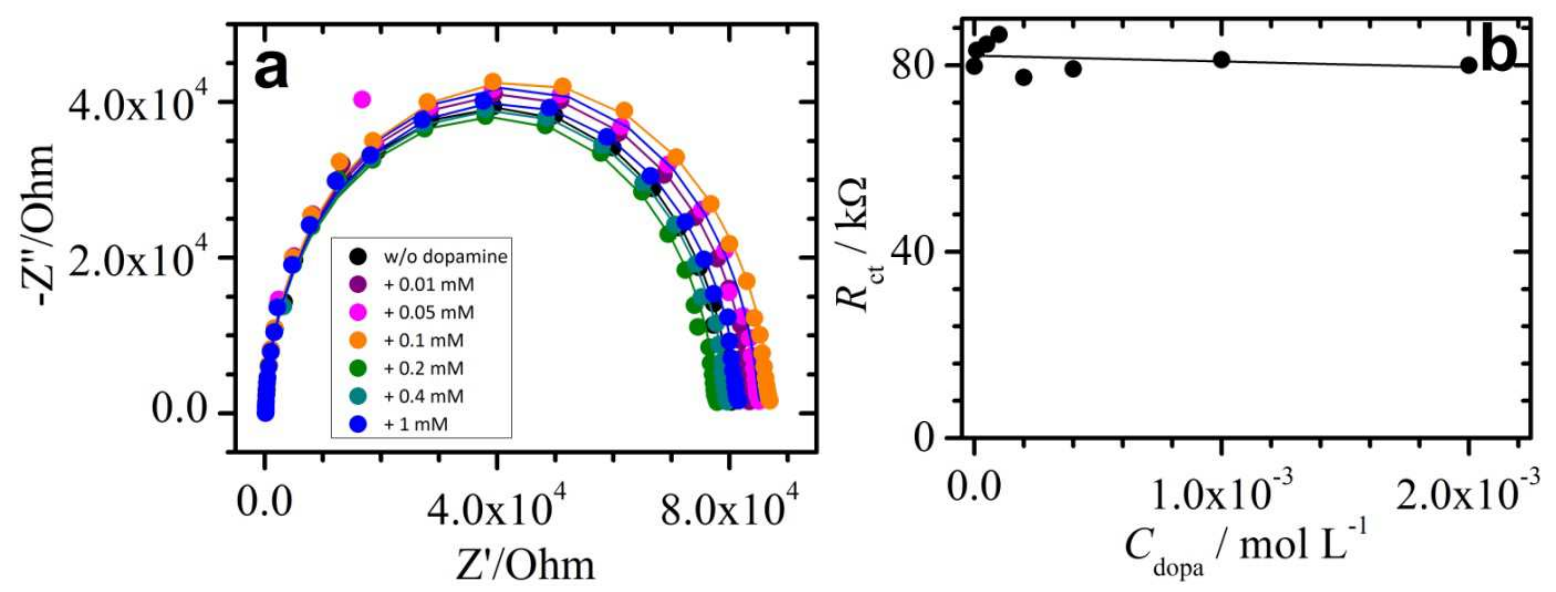

Figure 4. Nyquist $\left(-Z^{\prime \prime} v s . Z\right)$ plots for the $\mathbf{S i - E B}$ surface at pH $7.4+2 \mathrm{mM} \mathrm{Fe}(\mathrm{CN}) 6^{3-} / \mathrm{Fe}(\mathrm{CN}) 6^{4-}$ in the absence of dopamine and with increasing concentrations of dopamine (a). Applied potential: $0.15 \mathrm{~V}$ vs SCE. The filled dots are the experimental data and the solid lines correspond to the fitted curves assuming a Randles equivalent electrical circuit. (b) Corresponding $R_{\mathrm{ct}}-$ (DA concentration) plot.

The observed trend for the $R_{\text {ct }}$ decrease at the Si-EBBA surface with DA concentration may seem counterintuitive and thus requires some clarification. As a matter of fact, electrostatic, electronic and steric effects can be involved to explain the facilitated charge transfer of $\mathrm{Fe}(\mathrm{CN}) 6^{3-}$ $/ \mathrm{Fe}(\mathrm{CN})_{6}{ }^{4-}$ upon binding of DA. At $\mathrm{pH} 7.4$, the electrostatic repulsions between the negatively 
charged surface and the redox probe are believed to be gradually lowered upon the binding of DA because the negative charge on the boron atom is in fact counterbalanced by the positive charge of the ammonium group of DA. Steric effects can be also considered to account for DAinduced impedance changes. The binding of DA to the immobilized boronate species may lead to some monolayer disordering caused by the steric hindrance of DA. Due to these steric constraints, the penetration of the redox probe between the molecular chains would therefore be made easier. Another plausible explanation could be related to a dopamine-induced modification

of electron transfer kinetics. As elegantly demonstrated for dopamine-modified electrodes, ${ }^{52}$ the dopamine moieties bound to the silicon surface could lead to an electron transfer activation toward the redox probe in solution, acting as catalytic sites for adsorption or electron transfer or decreasing the hydrophobicity of the silicon surface.

\section{Conclusions}

In this work, boronic acid-terminated monolayers have been covalently bound to oxide-free hydrogen-terminated $\mathrm{Si}(111)$ surfaces using a one-step hydrosilylation route. This grafting procedure resulted in the formation of densely packed monolayers with a surface coverage of $0.34 \pm 0.04$ ethylbenzene boronic acid chain per surface silicon atom. The binding of dopamine to the immobilized boronic acid moieties at $\mathrm{pH} 7.4$ led to an easier charge transfer of the $\mathrm{Fe}(\mathrm{CN})_{6}^{3-} / \mathrm{Fe}(\mathrm{CN}){ }_{6}^{4-}$ reporter couple. Such functionalized surfaces showed a dopamine-sensitive impedimetric response with a detection limit below $10 \mu \mathrm{M}$ and without interference of the ascorbic acid.

It is worth recalling that biologically meaningful concentrations of dopamine under in vivo conditions are usually in the range of $10-50 \mathrm{nM} \cdot{ }^{53}$ However, much larger concentration levels (until $50 \mu \mathrm{M}$ ) have been detected when the dopamine release was electrically stimulated. ${ }^{54}$ 
Consequently, the system proposed herein would be capable of detecting such concentrations. Moreover, it is believed that the detection sensitivity could be significantly improved using either a more sensitive electrochemical technique (e.g. differential pulse voltammetry with corrected background signals) or a miniaturized configuration (e.g. chemical field-effect transistor) which would be more appropriate for detection of dopamine within the mammalian brain.

Finally, some characteristics of the responsive monolayer could be also optimized in order to enhance the sensitivity parameter. Towards this goal, the dilution of the boronic acid-terminated chains with other molecular chains could be a promising strategy. Indeed, this should enable control of the surface coverage of the boronic acid units and improvement of both the quality and the packing density of the resulting mixed monolayer. In the case where the diluting chains are electrochemically active, we anticipate that the electrochemical detection of dopamine could operate without the need of a reporter couple in solution. In the future, silicon-based electronic devices incorporating such functional monolayers could be exploited for the real-time monitoring of levels of dopamine under physiological conditions.

Finally, it is obvious that the proposed approach that combines monolayer system and electrochemical detection method could be extended to other diols, such as sugars.

Supporting Information. Supplementary figures showing XPS survey spectrum of the boronic acid-modified silicon surface, ${ }^{11} \mathrm{~B}$ NMR spectra of vinylbenzeneboronic acid in the absence and presence of dopamine and cyclic voltammograms of dopamine at a Pt working electrode. This material is available free of charge via the Internet at http://pubs.acs.org. 


\section{AUTHOR INFORMATION}

\section{Corresponding Author}

*E-mail: fabre@univ-rennes1.fr

\section{ORCID}

Bruno Fabre: 0000-0002-0488-7812

\section{Author Contributions}

The manuscript was written through contributions of all authors.

\section{Notes}

The authors declare no competing financial interest.

\section{ACKNOWLEDGMENT}

S. Ababou-Girard (Institut de Physique de Rennes, UMR 6251 CNRS, Département Matériaux Nanosciences, Université de Rennes 1, Campus de Beaulieu, 35042 Rennes Cedex, France) and C. Orione (Synthèse Caractérisation ANalyse de la MATière ScanMAT - UMS CNRS 2001) are fully acknowledged for XPS and ${ }^{11}$ B NMR measurements, respectively. 


\section{REFERENCES}

(1) Li, M.; Zhu, W.; Marken, F.; James, T. D. Electrochemical Sensing Using Boronic Acids. Chem. Commun. 2015, 51, 14562-14573.

(2) Bull, S. D.; Davidson, M. G.; Van Den Elsen, J. M. H.; Fossey, J. S.; Jenkins, A. T. A.; Jiang, Y.-B.; Kubo, Y.; Marken, F.; Sakurai, K.; Zhao, J.; James, T. D. Exploiting the Reversible Covalent Bonding of Boronic Acids: Recognition, Sensing, and Assembly. Acc. Chem. Res. 2013, 46, 312-326.

(3) Carey, R. I.; Folkers, J. P.; Whitesides, G. M. Self-Assembled Monolayers Containing $\omega-$ Mercaptoalkylboronic Acids Adsorbed onto Gold Form a Highly Cross-Linked, Thermally Stable Borate Glass Surface. Langmuir 1994, 10, 2228-2234.

(4) Kanayama, N.; Kitano, H. Interfacial Recognition of Sugars by Boronic Acid-Carrying Self-Assembled Monolayer. Langmuir 2000, 16, 577-583.

(5) Park, J.-Y.; Chang, B.-Y.; Nam, H.; Park, S.-M. Selective Electrochemical Sensing of Glycated Hemoglobin (HbA1c) on Thiophene-3-Boronic Acid Self-Assembled Monolayer Covered Gold Electrodes. Anal. Chem. 2008, 80, 8035-8044.

(6) Shervedani, R. K.; Bagherzadeh, M. Electrochemical Characterization of In Situ Functionalized Gold Cysteamine Self-Assembled Monolayer with 4-Formylphenylboronic Acid for Detection of Dopamine. Electroanalysis 2008, 20, 550-557.

(7) Casalini, S.; Leonardi, F.; Cramer, T.; Biscarini, F. Organic Field-Effect Transistor for Label-Free Dopamine Sensing. Org. Electron. 2013, 14, 156-163. 
(8) Liang, L.; Liu, Z. A Self-Assembled Molecular Team of Boronic Acids at the Gold Surface for Specific Capture of cis-Diol Biomolecules at Neutral pH. Chem. Commun. 2011, 47, 2255 2257.

(9) Vahlberg, C.; Linares, M.; Norman, P.; Uvdal, K. Phenylboronic Ester- and Phenylboronic Acid-Terminated Alkanethiols on Gold Surfaces. J. Phys. Chem. C 2012, 116, 796-806.

(10) Wannapob, R.; Kanatharana, P.; Limbut, W.; Numnuam, A.; Asawatreratanakul, P.; Thammakhet, C.; Thavarungkul, P. Affinity Sensor using 3-Aminophenylboronic Acid for Bacteria Detection. Biosens. Bioelectron. 2010, 26, 357-364.

(11) Li, D.; Chen, Y.; Liu, Z. Boronate Affinity Materials for Separation and Molecular Recognition: Structure, Properties and Applications. Chem. Soc. Rev. 2015, 44, 8097-8123.

(12) Shoji, E.; Freund, M. S. Potentiometric Sensors Based on the Inductive Effect on the pKa of Poly(aniline): a Nonenzymatic Glucose Sensor. J. Am. Chem. Soc. 2001, 123, 3383-3384.

(13) Shoji, E.; Freund, M. S. Potentiometric Saccharide Detection Based on the pKa Changes of Poly(Aniline Boronic Acid). J. Am. Chem. Soc. 2002, 124, 12486-12493.

(14) Fabre, B.; Taillebois, L. Poly(Aniline Boronic Acid)-Based Conductimetric Sensor of Dopamine. Chem. Commun. 2003, 2982-2983.

(15) Rick, J.; Chou, T.-C. Amperometric Protein Sensor - Fabricated as a Polypyrrole, PolyAminophenylboronic Acid Bilayer. Biosens. Bioelectron. 2006, 22, 329-335. 
(16) Ali, S. R.; Parajuli, R. R.; Ma, Y.; Balogun, Y.; He, H. Interference of Ascorbic Acid in the Sensitive Detection of Dopamine by a Nonoxidative Sensing Approach. J. Phys. Chem. B 2007, 111, 12275-12281.

(17) Zhong, M.; Teng, Y.; Pang, S.; Yan, L.; Kan, X. Pyrrole-Phenylboronic Acid: A Novel Monomer for Dopamine Recognition and Detection Based on Imprinted Electrochemical Sensor. Biosens. Bioelectron. 2015, 64, 212-218.

(18) Frank, M. M.; Chabal, Y. J. Surface and Interface Chemistry for Gate Stacks on Silicon. In Into the Nano Era; Springer: New York, 2009; pp 113-168.

(19) Higashi, G. S.; Chabal, Y. J.; Trucks, G. W.; Raghavachari, K. Ideal Hydrogen Termination of the Si(111) Surface. Appl. Phys. Lett. 1990, 56, 656-658.

(20) Yablonovitch, E.; Allara, D. L.; Chang, C. C.; Gmitter, T.; Bright, T. B. Unusually Low Surface-Recombination Velocity on Silicon and Germanium Surfaces. Phys. Rev. Lett. 1986, 57, $249-252$.

(21) Aureau, D.; Chabal, Y. J. Formation of Organic Monolayers through Wet Chemistry. In Functionalization of Semiconductor Surfaces; Tao, F., Bernasek, S. L., Eds.; Wiley \& Sons, Inc.: Hoboken, NJ, 2012; pp 301-338.

(22) Thissen, P.; Seitz, O.; Chabal, Y. J. Wet Chemical Surface Functionalization of OxideFree Silicon. Prog. Surf. Sci. 2012, 87, 272-290. 
(23) Ciampi, S.; Harper, J. B.; Gooding, J. J. Wet Chemical Routes to the Assembly of Organic Monolayers on Silicon Surfaces via the Formation of Si-C Bonds: Surface Preparation, Passivation and Functionalization. Chem. Soc. Rev. 2010, 39, 2158-2183.

(24) Li, Y.; Calder, S.; Yaffe, O.; Cahen, D.; Haick, H.; Kronik, L.; Zuilhof, H. Hybrids of Organic Molecules and Flat, Oxide-Free Silicon: High-Density Monolayers, Electronic Properties, and Functionalization. Langmuir 2012, 28, 9920-9929.

(25) Buriak, J. M. Organometallic Chemistry on Silicon and Germanium Surfaces. Chem. Rev. 2002, 102, 1271-1308.

(26) Wayner, D. D. M.; Wolkow, R. A. Organic Modification of Hydrogen Terminated Silicon Surfaces. J. Chem. Soc., Perkin Trans. 2 2002, 23-34.

(27) Fabre, B. Functionalization of Oxide-Free Silicon Surfaces with Redox-Active Assemblies. Chem. Rev. 2016, 116, 4808-4849.

(28) Sze, S. M. In Physics of Semiconductor Devices, 2nd ed.; J. Wiley \& Sons: New York, 2005.

(29) International Technology Roadmap for Semiconductors (ITRS): Process Integration, Devices, and Structures. Semiconductor Industry Association: San Jose, CA, 2013. http://www.itrs.net/reports.html.

(30) Iversen, L. L.; Iversen, S. D.; Dunnett, S. B.; Bjorklund, A. In Dopamine Handbook; Oxford University Press: Oxford, 2010. 
(31) Ye, N.; Neumeyer, J. L.; Baldessarini, R. J.; Zhen, X.; Zhang, A. Update 1 of: Recent Progress in Development of Dopamine Receptor Subtype-Selective Agents: Potential Therapeutics for Neurological and Psychiatric Disorders. Chem. Rev. 2013, 113, PR123-PR178.

(32) Yoshitake, T.; Kehr, J.; Yoshitake, S.; Fujino, K.; Nohta, H.; Yamaguchi, M. Determination of Serotonin, Noradrenaline, Dopamine and Their Metabolites in Rat Brain Extracts and Microdialysis Samples by Column Liquid Chromatography with Fluorescence Detection following Derivatization with Benzylamine and 1,2-Diphenylethylenediamine. $J$. Chromatography B 2004, 807, 177-183.

(33) Du, M.; Flanigan, V.; Ma, Y. Simultaneous Determination of Polyamines and Catecholamines in PC-12 Tumor Cell Extracts by Capillary Electrophoresis with Laser-Induced Fluorescence Detection. Electrophoresis 2004, 25, 1496-1502.

(34) Hows, M. E. P.; Lacroix, L.; Heidbreder, C.; Organ, A. J.; Shah, A. J. High-Performance Liquid Chromatography/Tandem Mass Spectrometric Assay for the Simultaneous Measurement of Dopamine, Norepinephrine, 5-Hydroxytryptamine and Cocaine in Biological Samples. $J$. Neuroscience Methods 2004, 138, 123-132.

(35) Tan, L.; Zhou, K.-G.; Zhang, Y.-H.; Wang, H.-X.; Wang, X.-D.; Guo, Y.-F.; Zhang, H.-L. Nanomolar Detection of Dopamine in the Presence of Ascorbic Acid at $\beta$ Cyclodextrin/Graphene Nanocomposite Platform. Electrochem. Commun. 2010, 12, 557-560.

(36) Abbaspour, A.; Noori, A. A Cyclodextrin Host-Guest Recognition Approach to an Electrochemical Sensor for Simultaneous Quantification of Serotonin and Dopamine. Biosens. Bioelectron. 2011, 26, 4674-4680. 
(37) Casalini, S.; Leonardi, F.; Cramer, T.; Biscarini, F. Organic Field-Effect Transistor for Label-Free Dopamine Sensing. Org. Electron. 2013, 14, 156-163.

(38) Wade, C. P.; Chidsey, C. E. D. Etch-Pit Initiation by Dissolved Oxygen on Terraces of HSi(111). Appl. Phys. Lett. 1997, 71, 1679-1682.

(39) Linford, M. R.; Fenter, P.; Eisenberger, P. M.; Chidsey, C. E. D. Alkyl Monolayers on Silicon Prepared from 1-Alkenes and Hydrogen-Terminated Silicon. J. Am. Chem. Soc. 1995, $117,3145-3155$.

(40) Haj-Yahia, A.-E.; Yaffe, O.; Bendikov, T.; Cohen, H.; Feldman, Y.; Vilan, A.; Cahen, D. Substituent Variation Drives Metal/Monolayer/Semiconductor Junctions from Strongly Rectifying to Ohmic Behavior. Adv. Mater. 2013, 25, 702-706.

(41) Narkar, A. R.; Barker, B.; Clisch, M.; Jiang, J.; Lee, B. P. pH Responsive and Oxidation Resistant Wet Adhesive based on Reversible Catechol-Boronate Complexation. Chem. Mater. 2016, 28, 5432-5439.

(42) Hendrickson, D. N.; Hollander, J. M.; Jolly, W. L. Core-Electron Binding Energies for Compounds of Boron, Carbon, and Chromium. Inorg. Chem. 1970, 9, 612-615.

(43) Powell, C. J.; Jablonski, A. NIST Electron Effective Attenuation Length Database; National Institute of Standards and Technology: Gaithersburg, MD, 2001.

(44) Cicero, R. L.; Linford, M. R.; Chidsey, C. E. D. Photoreactivity of Unsaturated Compounds with Hydrogen-Terminated Silicon(111). Langmuir 2000, 16, 5688-5695. 
(45) Henry de Villeneuve, C.; Pinson, J.; Bernard, M. C.; Allongue, P. Electrochemical Formation of Close-Packed Phenyl Layers on Si(111). J. Phys. Chem. B 1997, 101, 2415-2420.

(46) Harada, Y.; Koitaya, T.; Mukai, K.; Yoshimoto, S.; Yoshinobu, J. Spectroscopic Characterization and Transport Properties of Aromatic Monolayers Covalently Attached to Si(111) Surfaces. J. Phys. Chem. C 2013, 117, 7497-7505.

(47) Liu, Y.; Ai, K.; Lu, L. Polydopamine and Its Derivative Materials: Synthesis and Promising Applications in Energy, Environmental, and Biomedical Fields. Chem. Rev. 2014, $114,5057-5115$.

(48) Ptak, T.; Mlynarz, P.; Dobosz, A.; Rydzewska, A.; Prokopowicz, M. Potentiometric and NMR Complexation Studies of Phenylboronic Acid PBA and its Aminophosphonate Analog with Selected Catecholamines. J. Mol. Struct. 2013, 1040, 59-64.

(49) Lorand, J. P.; Edwards, J. O. Polyol Complexes and Structure of the Benzeneboronate Ion. J. Org. Chem. 1959, 24, 769-774.

(50) James, T. D.; Samankumara Sandanayake, K. R. A.; Shinkai, S. Saccharide Sensing with Molecular Receptors Based on Boronic Acid. Angew. Chem., Int. Ed. Engl. 1996, 35, 1910-1922.

(51) Tomsho, J. W.; Benkovic, S. J. Elucidation of the Mechanism of the Reaction between Phenylboronic Acid and a Model Diol, Alizarin Red S. J. Org. Chem. 2012, 77, 2098-2106.

(52) Ghilane, J.; Hauquier, F.; Lacroix, J.-C. Oxidative and Stepwise Grafting of Dopamine Inner-Sphere Redox Couple onto Electrode Material: Electron Transfer Activation of Dopamine. Anal. Chem. 2013, 85, 11593-11601. 
(53) Robinson, D. L.; Hermans, A.; Seipel, A. T.; Wightman, R. M. Monitoring Rapid Chemical Communication in the Brain. Chem. Rev. 2008, 108, 2554-2584.

(54) Wightman, R. M.. Kuhr, W. G.; Ewing, A. G. Voltammetric Detection of Dopamine Release in the Rat Corpus Striatum. Ann. N. Y. Acad. Sci. 1986, 473, 92-105. 